\title{
Desafios e perspectivas para a hidrografia portuária e petrolífera no Brasil
}

\author{
Marcelo Sperle Dias, Universidade do Estado do Rio de Janeiro
}

Copyright 2021, SBGf - Sociedade Brasileira de Geofísica.

This paper was prepared for presentation during the $17^{\text {th }}$ International Congress of the Brazilian Geophysical Society held in Rio de Janeiro, Brazil, $16-19$ August 2021.

Contents of this paper were reviewed by the Technical Committee of the $17^{\text {th }}$ International Congress of the Brazilian Geophysical Society and do not necessarily represent any position of the SBGf, its officers or members. Electronic reproduction or storage of any part of this paper for commercial purposes without the written consent of the Brazilian Geophysical Society is prohibited.

\section{Resumo}

A hidrografia é uma ciência multi e transdisciplinar que tem como base várias outras áreas do conhecimento, como: a oceanografia, a geologia, a geofísica, a cartografia e a geodésia. É uma ciência essencial para diversos setores estratégicos da sociedade, seja para a economia, infraestrutura, desenvolvimento, inovação, energia, soberania ou questões socioambientais. Desta forma a sua aplicação deve ser feita de forma integrada, por profissionais experientes oriundos destas áreas do conhecimento. Neste contexto, existem ainda grandes desafios para a hidrografia portuária e petrolífera no Brasil. Dentre estes, pode-se citar: o alto custo dos equipamentos, das embarcações, dos softwares e dos profissionais sêniores; o que onera os contratos e inviabiliza ou retarda os investimentos e o crescimento de vários desses setores. Outro aspecto relevante, é a carência de empresas no Brasil capacitadas para prestar serviços de manutenção, reposição e calibração nos inúmeros equipamentos eletrônicos, de alta precisão; necessários para atender as exigências da Autoridade Marítima, Portuária e das Operadoras das indústrias de O\&G, energias renováveis e hidrovias, dentre outras. Soma-se a essas dificuldades o pequeno contingente de profissionais habilitados no país; onde apenas a Marinha do Brasil oferece um curso de excelência para a formação de hidrógrafos, certificado pela Organização Hidrográfica Internacional $(\mathrm{OHI})$. Como consequência dessas dificuldades, geralmente, os levantamentos hidrográficos são muito prejudicados, tanto na aquisição, quanto no processamento e interpretação dos dados; necessitando de grande esforço de retrabalho e causando prejuízos aos contratantes, gestores e tomadores de decisão. Outro aspecto relevante é a falta ou carência de legislação específica e diferenciada, como por exemplo no caso das hidrovias e das embarcações autônomas (USV's ou "veículos de superfície não tripulados"). São, portanto, alguns desafios que o Brasil precisa transpor para atender as necessidades de expansão desses vários setores estratégicos e às exigências das normas internacionais. Por outro lado, todos esses desafios geram também boas oportunidades e perspectivas para as empresas e profissionais que investirem, de forma diligente e estratégica, na busca de conhecimento e soluções inovadores para esses setores. Todos esses aspectos são apresentados e discutidos na presente palestra; fruto de uma profícua parceria entre o Programa de Geologia e Geofísica Marinha (PGGM), a Sociedade Brasileira de Geofísica (SBGf), a Associação Brasileira de Oceanografia (AOCEANO), a Associação Brasileira de Estudos do Quaternário (ABEQUA) e a Sociedade Brasileira de Hidrografia (SBHidro). 